\title{
Postoperativ smerte
}

\section{hos pasienter innlagt i norske sykehus ำ}

\begin{abstract}
Sammendrag
Bakgrunn. Postoperativ smertebehandling har betydning for pasientens velbefinnende og fremmer mobilisering, forkorter liggetid og forebygger postoperative komplikasjoner. Basert på data om postoperativ smerte fra andre land, norske data om smerte hos kreftpasienter samt klinisk erfaring, var det forventet at en betydelig andel av innlagte pasienter i norske sykehus opplever sterke postoperative smerter.
\end{abstract}

Materiale og metode. 215 inneliggende pasienter fordelt på 14 norske sykehus deltok i en studie av smerte det første postoperative døgnet. Studien er basert på pasientenes egenrapporterte data og data fra pasientjournaler.

Resultater. Gjennomsnittlig smerteintensitet første postoperative døgn var 3,0 (SD 2,1) på en 11-punkts numerisk skala. $38 \%$ av pasientene rapporterte gjennomsnittlig smerte $\geq 4$, mens $11 \%$ rapporterte gjennomsnittlig smerte $\geq 6$. $8 \%$ av pasientene rapporterte at selv svakeste smerte i ro hadde vært $\geq 4$. Intensitet av postoperativ smerte var kun dokumentert i journalen til $22 \%$ av pasientene. Svar fra pasientene indikerte at $52 \%$ var blitt bedt om å angi smerteintensitet på en skala, mens henholdsvis $78 \%$ og $74 \%$ var blitt spurt om behov for ekstra smertestillende og om de hadde effekt av de smertestillende medisinene.

Fortolkning. Mange pasienter rapporterer sterke smerter første postoperative døgn. Det er et betydelig forbedringspotensial for kartlegging, dokumentasjon og behandling av smerte.
Olav Magnus S. Fredheim

olav.m.fredheim@ntnu.no

Nasjonalt kompetansesenter

for sammensatte lidelser

og

Forskningsgruppe smerte og palliasjon Institutt for sirkulasjon og bildediagnostikk Det medisinske fakultet

Norges teknisk-naturvitenskapelige universitet og

Klinikk for akuttmedisin

Sykehuset Telemark

\section{Gunnvald Kvarstein}

Smerteseksjonen

Anestesi og intensivklinikken

Rikshospitalet

Oslo universitetssykehus

\section{Eva Undall}

Smerteenheten

Klinikk for akuttmedisin

Sykehuset Telemark

\section{Audun Stubhaug}

Avdeling for smertebehandling

Oslo universitetssykehus

\section{Tone Rustøen}

Rikshospitalet

Oslo universitetssykehus

og

Høyskolen i Oslo

\section{Petter C. Borchgrevink}

Nasjonalt kompetansesenter

for sammensatte lidelser

og

Forskningsgruppe smerte og palliasjon Institutt for sirkulasjon og bildediagnostikk

Norges teknisk-naturvitenskapelige universitet og

Avdeling for smerte og sammensatte lidelser Klinikk for anestesi og akuttmedisin

St. Olavs hospital

Etter kirurgiske inngrep som er for omfattende til å utføres som dagkirurgi, vil vanligvis smertene uten behandling variere fra moderate til svært intense. Dersom man derimot planlegger smertebehandlingen godt, evaluerer smertene systematisk i den postoperative fasen og benytter de medikamenter og metoder som er tilgjengelige, er det forfatternes erfaring at postoperative smerter kan lindres effektivt. God behandling av de mest krevende smertetilstandene krever involvering av et kompetent smerteteam (1).

God postoperativ smertebehandling har betydning for pasientens velbefinnende, men har også vist å fremme mobilisering, forkorte liggetid og forebygge postoperative komplikasjoner knyttet til hjerte og lunger (2). Dette forholdet er imidlertid best studert og dokumentert for bruk av epiduralanalgesi hos de sykeste pasientene og etter større inngrep. Det er også holdepunkter for at kvaliteten på den postoperative smertebehandlingen og valget av medikamenter som brukes, påvirker risikoen for å utvikle kronisk smerte og hyperestesi i operasjonsområdet $(3,4)$.

Det er ikke publisert data som viser i hvilken grad pasienter i norske sykehus mottar effektiv smertebehandling etter operasjoner. Imidlertid har tidligere undersøkelser vist at $23 \%$ av kreftpasienter i norske sykehus hadde intense til uutholdelige smerter uten å motta smertestillende behandling $(5,6)$. Når det gjelder prevalensstudier av postoperativ smerte, viser en undersøkelse fra Frankrike at $4,2 \%$ av postoperative pasienter hadde intense smerter i hvile - definert som $>7$ på en 11-punkts numerisk skala (NRS) - og $27 \%$ ved bevegelse, mens $51 \%$ opplevde slike intense smerter i løpet av den postoperative perioden (7). I en studie fra Nederland, der postoperativ smerte ble kartlagt hos 1490 fortløpende pasienter, rapporterte $30 \%$ av pasientene moderat eller sterk smerte i hvile, definert som $>40 \mathrm{~mm}$ på en $100 \mathrm{~mm}$ visuell analog skala (VAS) (8). Basert på funnene fra norske og utenlandske sykehus samt egne kliniske erfaringer, er det grunn til å anta at en betydelig andel av pasientene i norske sykehus ikke mottar tilstrekkelig postoperativ smertelindring. En vanlig målsetting for postoperativ smertebehandling er å oppnå en smerteintensitet på 3 eller lavere på en 11-punkts numerisk skala (NRS).

Denne studien har som mål å besvare følgende forskningsspørsmål:

- Hva er prevalensen av postoperativ smerte med intensitet $\geq 4$ på en 11-punkts numerisk skala første postoperative døgn hos pasienter innlagt i norske sykehus?

- I hvilken grad kartlegges postoperativ smerte systematisk i norske sykehus?

\section{Hovedbudskap}

- Mange pasienter rapporterer at de har hatt moderate til intense smerter postoperativt, særlig ved bevegelse

- Til tross for høye gjennomsnittlige smertenivåer var mange pasienter fornøyd

- Systematisk registrering og dokumentasjon av postoperativ smerte ble bare utført hos en femdel av pasientene 
- Hvilken behandling for postoperativ smerte gis til pasienter innlagt i norske sykehus?

\section{Materiale og metode \\ Studiedesign}

Studien ble gjennomført som en tverrsnittsundersøkelse ved 14 norske sykehus (e-tab 1). Data ble samlet inn enten onsdag eller torsdag i uke 22-23 i 2010. Både pasienter som hadde gjennomgått elektiv kirurgi og øyeblikkelig hjelp-kirurgi ble inkludert, og studien omfattet alle kirurgiske sengeposter/ spesialiteter. Som eneste unntak og på grunn av kapasitetsmessige og logistiske hensyn, ble pasienter ved Øyeavdelingen på Ullevål sykehus og pasienter operert som øyeblikkelig hjelp ved Aker sykehus ikke inkludert. Dagkirurgiske pasienter og barn $(<18$ år) inngår ikke i studien.

\section{Studiepopulasjon}

Voksne innlagte pasienter ( $>18$ år) ble inkludert forutsatt at de fylte et av de følgende inklusjonskriteriene:

- Pasienter som var operert foregående dag og ble flyttet fra oppvåkningsavdeling til vanlig sengepost senest kl 21.

- Pasienter som var operert to dager tidligere, men overflyttet til sengepost senere enn kl 21 operasjonsdagen.

- Pasienter som etter operasjonen ble overvåket ved intensivavdeling eller oppvåkningsavdelingen, ble inkludert dersom det før datainnsamlingen var gått 14 timer eller mer siden operasjonen.

For å sikre et representativt utvalg av pasienter ble intervjuene på hver avdeling gjort $\mathrm{i}$ alfabetisk rekkefølge (etter etternavn). Man ville derved unngå at de inkluderte pasientene systematisk skilte seg fra ikke-inkluderte pasienter om det ikke ble tid til å intervjue alle pasientene.

For pasienter som fylte inklusjonskriteriene, men ikke deltok i studien, registrerte vi årsaken til at de ikke deltok (e-fig 1). Gjennomsnittsalderen for pasienter som ikke ble inkludert, var 61,6 år.

\section{Datainnsamling}

Alle data ble registrert på standardisert skjema. Sosiodemografiske variabler, opplysninger om det kirurgiske inngrepet og narkosen/bedøvelsen ble hentet i pasientjournalen og opplysninger om den forordnede postoperative smertebehandlingen ble hentet fra journal og kurve. Pasientens egenrapportering omfattet seks spørsmål om smerteintensitet (11-punkts numerisk smerteskala forankret $\mathrm{i}$ punktene $\ll 0=$ ingen smerte» og $« 10=$ verst tenkelige smerte»), åtte spørsmål om smertebehandlingen og et spørsmål om hvilket av symptomene smerte, kvalme, slapphet eller engstelse/uro som hadde vært mest plagsomt etter operasjonen. Detaljert beskrivelse av datainnsamlingen finnes i e-ramme 1 (9-11).

\begin{tabular}{|c|c|c|c|c|c|}
\hline & $\begin{array}{l}\text { Gjennom- } \\
\text { snitt (SD) }\end{array}$ & Andel $\leq 2^{1}$ & Andel $\leq 3^{1}$ & Andel $\leq 5^{1}$ & Andel $\leq 71$ \\
\hline Gjennomsnittlig smerte & $3,0(2,1)$ & 46,0 & 62,4 & 89,2 & 96,7 \\
\hline Svakeste smerte ved bevegelse ${ }^{2}$ & $2,4(2,1)$ & 61,2 & 78,5 & 90,2 & 97,2 \\
\hline Sterkeste smerte ved bevegelse ${ }^{2}$ & $4,7(2,9)$ & 29,3 & 38,1 & 58,6 & 79,1 \\
\hline Svakeste smerte i ro & $1,3(1,6)$ & 83,3 & 91,6 & 97,7 & 99,1 \\
\hline Sterkeste smerte i ro & $3,4(2,8)$ & 45,0 & 57,8 & 77,7 & 88,6 \\
\hline Smerte akkurat nå & $2,0(2,1)$ & 68,4 & 78,1 & 92,1 & 98,1 \\
\hline
\end{tabular}

\section{Etikk}

Studien er godkjent av regional komité for medisinsk og helsefaglig forskningsetikk (REK Sør-Øst). Pasientene mottok muntlig og skriftlig informasjon om studien og ga informert samtykke til å delta. Ved hvert av de deltakende sykehusene ble tillatelse til datainnsamlingen innhentet både fra sykehusledelsen og fra avdelingsledelsen samt fra det lokale personvernombudet $\mathrm{i}$ de tilfellene det var aktuelt.

\section{Statistikk og analyse}

For studien var det ikke mulig å gjøre statistisk beregning av utvalgsstørrelse eller styrke i forkant. Betraktninger om utvalgsstørrelsen presenteres i e-ramme 2 . Ved innskanning av registreringsskjemaene ble resultatet registrert som manglende data i de tilfellene der det var krysset av for flere svaralternativer på spørsmål/variabler der det kun skulle krysses av for ett alternativ. SPSS 17.0 for Windows ble benyttet til administrasjon av data og til analyser. For alder og smerteintensitet oppgis gjennomsnitt og standardavvik. For øvrige variabler angis fordeling av svarene med absolutte antall (N) og prosentandel. Der ikke annet er spesifisert, er prosentandelen beregnet blant de pasientene der man hadde data for den aktuelle variabelen. For de variablene som inngår $i$ analysene, var antallet pasienter med manglende data fra null til $11 \mathrm{i}$ de tilfellene der ikke annet er angitt.

\section{Resultater}

\section{Studiepopulasjon}

I studien ble 215 pasienter inkludert (e-fig 1). Gjennomsnittsalderen var 54,8 år (SD 18) og andelen kvinner var $53 \%$. Pasientkarakteristika er vist i e-tabell 2. Av pasientene hadde $163(78 \%)$ gjennomgått et elektivt inngrep, mens $46(22 \%)$ var operert som øyeblikkelig hjelp. Ved tidspunktet for datainnsamlingen var $187(88 \%)$ av pasientene flyttet til sengepost, mens 25 (12\%) fortsatt ble overvåket ved intensiv- eller oppvåkningsavdeling. På samme tidspunkt var 25 (13\%) sengeliggende, 16 (8\%) hadde vært mobilisert til sengekant, 11 (6\%) hadde vært mobilisert til stol, 58 (30\%) hadde vært oppegående med støtte og 86 (44\%) hadde vært oppegående uten støtte. For 19 pasienter manglet opplysninger om mobilisering.

\section{Mest plagsomme symptom}

77 pasienter $(43 \%)$ rapporterte at smerte hadde vært det mest plagsomme symptomet første postoperative døgn. Slapphet/tretthet, kvalme/oppkast og engstelse/uro ble rapportert som det mest plagsomme symptomet av henholdsvis $53(29 \%), 24$ (13\%) og 27 $(13 \%)$ pasienter. $34(16 \%)$ pasienter hadde ikke angitt hvilket symptom som var det mest plagsomme.

\section{Smerteintensitet}

Pasientene rapporterte etter operasjonen en gjennomsnittlig smerteintensitet på 3,0 (SD $2,1)$ (tab 3). For $38 \%$ og $11 \%$ av pasientene var gjennomsnittlig smerte henholdsvis $\geq 4$ og $\geq 6.8 \%$ av pasientene rapporterte at svakeste smerte i ro hadde vært $\geq 4$. For $62 \%$ av pasientene hadde de sterkeste smertene ved bevegelse (hoste, dype innpust eller forflytning) vært $\geq 4$, mens for $41 \%$ hadde de sterkeste smertene ved bevegelse vært $\geq 6$.

Gjennomsnittlig smerteintensitet hos pasienter med epidural smertelindring (data ikke vist) var nærmest identisk med studiepopulasjonen som helhet både i ro, ved bevegelse og i gjennomsnitt.

\section{Opplevelse av smertene}

På spørsmål om det hadde vært mer smerte enn forventet etter operasjonen, svarte 42 $(20 \%)$ ja, mens $52(24 \%)$ anga at smertene hadde vært som forventet. På tilsvarende spørsmål om hvorvidt det etter operasjonen hadde vært mindre smerte enn forventet, rapporterte $97(46 \%)$ mindre smerte enn forventet og $60(28 \%)$ at smerten hadde vært som forventet. Altså varierte antallet som svarte at smertene var som forventet, avhengig av spørsmålet som ble stilt. 192 $(91 \%)$ pasienter rapporterte at de var fornøyde med smertebehandlingen etter operasjonen.

\section{Smerteregistrering}

Mens 110 (52\%) pasienter rapporterte å ha blitt bedt om å angi smerteintensitet på en 
skala, hadde henholdsvis 167 (78\%) og 160 ( $78 \%$ ) blitt spurt om de hadde behov for ekstra smertestillende og om de hadde effekt av de smertestillende medisinene de fikk. Systematisk registrering av smerteintensitet minst tre ganger i døgnet eller før og etter «ved behov»-analgetika var dokumentert i journal eller kurve hos 43 (22\%) pasienter. Hos 17 pasienter manglet informasjon om systematisk smerteregistrering.

\section{Smertebehandling}

Det hyppigst, fast doserte analgetikum var paracetamol, som var forordnet til 194 (91\%) av pasientene (tab 4). Ikke-steroide antiinflammatoriske midler (NSAIDs) og steroider var forordnet til henholdsvis 47 $(22 \%)$ og 28 (13\%) pasienter. For steroider inkluderer dette tallet en engangsdose gitt under operasjonen. Den vanligste fast forordnede administrasjonsformen av opioider var depottabletter, forordnet til $48(23 \%)$ pasienter. Henholdsvis 41 (19\%), 15 (7\%) og seks (3\%) fikk fast forordnet epiduralanalgesi, påfyll av lokalanestetika i sårområdet eller vedvarende blokade av perifer nerve med påfyll av lokalanestetika via kateter. Blant de 111 pasientene som var under 65 år og var i ASA (American Society of Anesthesiologists)-gruppe 1 eller 2 var NSAIDpreparater forordnet til $33(30 \%)$ pasienter.

Den hyppigst forordnede behandlingen "ved behov mot smerte» var opioid injeksjon, forordnet til $135(63 \%)$ av pasientene. Opioidtabletter var forordnet ved behov til $67(32 \%)$ av pasientene.

\section{Medikamentdoser}

Hos 139 av 215 pasienter (65\%) var paracetamol forordnet før operasjonsstart. Av disse fikk 133 paracetamol oralt, mens fire og to pasienter fikk henholdsvis paracetamol intravenøst og rektalt. Blant pasientene som fikk forordnet paracetamol oralt, var det hos henholdsvis to $(1,5 \%), 44(33 \%), 60$ (45\%) og 27 (20\%) forordnet $0,5 \mathrm{~g}, 1 \mathrm{~g}, 1,5$ $\mathrm{g}$ og $2 \mathrm{~g}$ som preoperativ dose. Forordningen for intravenøs og rektal administrasjon var henholdsvis $1 \mathrm{~g}$ og $2 \mathrm{~g}$. Av de 176 pasientene som fikk forordnet paracetamol oralt etter operasjonen, fikk 11 (6\%) mindre enn $4 \mathrm{~g}$ første postoperative døgn, 154 (88\%) fikk $4 \mathrm{~g}$ første postoperative døgn og de resterende $11(6 \%) 6 \mathrm{~g}$ første postoperative døgn.

Opioidene som ble dosert fast første postoperative døgn, fordelte seg på flere medikamenter og et stort spenn av doser. Kombinasjonene av medikament, dose og administrasjonsform som forekom oftest, var oksykodontabletter $11-20 \mathrm{mg} /$ døgn (20 personer), oksykodontabletter inntil $10 \mathrm{mg} / \mathrm{d} ø g n(13$ personer) og oksykodon $21-40 \mathrm{mg} / \mathrm{d} ø g n$ (13 personer).

\section{Bruk av epiduralanalgesi}

Blant de 41 pasientene som ble behandlet med epidural smertelindring, fikk 39 (95\%) en medikamentblanding som inneholdt et opioid, mens antallet som fikk en medikamentblanding som inneholdt henholdsvis adrenalin eller et lokalanestetika var 36 $(88 \%)$. Altså fikk de fleste pasientene en medikamentblanding som inneholdt alle tre medikamentgruppene. Hos $28(68 \%)$ av pasientene som mottok epidural smertebehandling, var det i journalen dokumentert utbredelse av sensorisk blokade. Blant pasienter som hadde epidural smertelindring, rapporterte $21 \%$ smerte som mest plagsomme symptom.

\section{Informasjon}

$137(67 \%)$ av pasientene rapporterte at de før operasjonen hadde fått informasjon om smertebehandlingen og postoperative smerter. $40(19 \%)$ pasienter rapporterte at de hadde fătt informasjon om at det var risiko for å utvikle kroniske postoperative smerter.

\section{Diskusjon}

Denne studien har vist at to av fem pasienter innlagt i norske sykehus rapporterer en gjennomsnittlig smerte som er $\geq 4$ det første postoperative døgnet og at en av ti angir $\geq 6$. Videre har studien vist at en av 12 pasienter $(8 \%)$ rapporterer at selv den svakeste smerten i ro har vært $\geq 4$ det første postoperative døgnet. Til tross for dette angir mer enn $90 \%$ av pasientene at de er fornøyde med den postoperative smertebehandlingen. Disse funnene bekrefter det som tidligere er vist i studier fra andre land: Det er en høy andel av pasienter som rapporterer moderat til intens postoperativ smerte $(7,8)$.

Et viktig funn fra denne undersøkelsen er at postoperativ smerte bare er dokumentert systematisk i journalen til $22 \%$ av pasientene i studien. Etter forfatternes syn bør god praksis for postoperativ smertebehandling innebære at smerteintensitet kartlegges minst tre ganger i døgnet, at pasienten tilbys «ved behov»-medikasjon ved smerteintensitet over 3 og at smerteintensitet skal reevalueres etter at «ved behov»-medikasjon er gitt. Bare halvparten av alle pasientene var blitt bedt om å angi smerte på en skala, men derimot var tre av fire tilbudt ekstra smertestillende. Tidligere er det rapportert at pasientene venter med å be om ekstra smertestillende til smerten oppleves som intens (7). Dersom smerte ikke kartlegges systematisk, risikerer vi at mange pasienter ligger med vedvarende sterke smerter som både forhindrer mobilisering og øker faren for komplikasjoner.

Det er videre grunn til å bemerke at bare et lite mindretall av pasientene angir å ha mottatt informasjon om risikoen for å utvikle kroniske postoperative smerter. Prevalensen og alvorlighetsgraden av kronisk postoperativ smerte varierer i ulike materialer, og er nok i stor grad knyttet til inngrepet og den kirurgiske teknikken. Likevel angir de fleste studiene en prevalens på $>10 \%$ (3). Informasjon om risiko for kronisk smerte bør avstemmes mot hvor sterk indikasjonen for inngrepet er og det som er kjent om risiko for utvikling av kronisk postoperativ smerte etter det aktuelle inngrepet. Informasjonen må tilpasses den enkelte pasient og ta høyde for at smerter før operasjonen er en sterk prediktor for kronisk postoperativ smerte. Unntaksvis kan det være riktig å ikke informere om risikoen for utvikling av kronisk smerte. Når så mange pasienter rapporterer at de ikke har fått informasjon om denne risikoen, indikerer det imidlertid at mange pasienter mangler vesentlig informasjon for å gi samtykke til operasjon.

\section{Medikamenter}

Av smertestillende medikamenter/behandlinger som er forordnet til faste tider, har bare paracetamol en høy prevalens $(91 \%)$. Dette er positivt fordi paracetamol gir en klar additiv effekt til opioider og er uten vesentlige bivirkninger. Forekomsten av fast forordning av NSAID-preparater og steroider var henholdsvis $22 \%$ og $13 \%$. Det foreligger i dag god vitenskaplig dokumentasjon på effekt av NSAID-preparater ved postoperativ smerte (12-14). Imidlertid kan disse føre til alvorlige bivirkninger. De bør derfor ikke gis rutinemessig til pasienter med kjente risikofaktorer for de vanlige bi-

Tabell 4 Postoperativ smertebehandling i norske sykehus. Antall og andel pasienter som har fått forordnet hver behandling første postoperative $\mathrm{d} ø \mathrm{gn}$

\begin{tabular}{lrr}
\hline Behandling & N & \multicolumn{1}{c}{$\%$} \\
\hline $\begin{array}{l}\text { Faste doser/kontinuerlig/ } \\
\text { basisanalgesi }\end{array}$ & & \\
\hline Paracetamol & 194 & 91,1 \\
\hline NSAID-preparater & 47 & 22,1 \\
\hline Steroider & 28 & 13,1 \\
\hline Opioid depottablett & 48 & 22,5 \\
\hline Opioid tablett likke depot) & 16 & 7,5 \\
\hline Opioid plaster & 2 & 0,9 \\
\hline Opioid injeksjon & 10 & 4,7 \\
\hline Opioid infusjon & 2 & 0,9 \\
\hline Opioid på pumpe for pasient- & 5 & 2,3 \\
kontrollert analgesi & 2 & 0,9 \\
\hline Gabapentin & 41 & 19,2 \\
\hline Epidural analgesi & 1 & 0,5 \\
\hline Intratekal analgesi & & \\
\hline Påfyll av lokalbedøvelse & 15 & 7 \\
i sårområdet & 6 & 2,8 \\
\hline Kateter for perifer nerveblokade & & \\
\hline & & \\
\hline Ved behov & 22 & 10,3 \\
\hline Paracetamol & & \\
\hline NSAID-preparater & 18 & 18,8 \\
\hline Opioid tablett & 87,5 \\
\hline Opioid injeksjon & 31,5 \\
\hline Pasientkontrollert analgesi & 4 & 63,4 \\
\hline Bolus på epiduralkateter & & \\
& & \\
\hline
\end{tabular}


virkningene. En annen mulig årsak til deres lave utbredelse kan være at man i eksperimentelle studier har indikert redusert hemostase og forsinket beintilheling, selv om det mangler robust dokumentasjon på at disse forholdene har klinisk betydning $(15,16)$. Når kun $30 \%$ av pasientene under 65 år og $\mathrm{i}$ ASA-gruppene 1 eller 2 får NSAID-preparater, tyder dette likevel på et generelt underforbruk av disse midlene. Steroider brukes perioperativt både for å redusere postoperativ kvalme og på grunn av sin smertelindrende effekt. En enkeltdose steroider er vist å være opioidsparende, men dokumentasjonen er best ved små og mindre inngrep, som hovedsakelig utføres som dagkirurgi (17).

Hos $63 \%$ av pasientene i studien var det forordnet opioidinjeksjoner ved behov. Opioidtabletter ved behov var forordnet hos halvparten så mange (32\%). Dette indikerer at de fleste pasientene har tilgang til potente analgetika. Imidlertid er det viktig å være klar over at en forordning i seg selv ikke betyr at pasienten får opioider når de har behov. Adekvat bruk av ekstra smertestillende må dokumenteres gjennom systematisk kartlegging av smertenivå og hva som blir gitt av analgetika ved høy skår.

\section{Epiduralanalgesi}

Mange av pasientene som mottok epiduralanalgesi, rapporterte likevel om betydelige smerter. Epiduralanalgesien var overveiende basert på en blanding av et opioid, lokalanestetikum og adrenalin, hvilket er en forutsetning for effektiv symptomkontroll (18, 19). Effektiv epiduralanalgesi krever imidlertid også individuell dosetitrering, og pasientene vil kunne trenge ekstra tilleggsdoser av epiduralblandingen. I vår undersøkelse fikk kun halvparten av pasientene med epiduralanalgesi forordnet ekstra bolusdoser ved behov. Mange av sykehusene/avdelingene synes derfor ikke å utnytte et viktig potensial ved epidural smertebehandling. Selv om pasienter med epiduralanalgesi oftere har gjennomgått større kirurgiske inngrep, kan disse manglene forklare hvorfor pasientene rapporterte samme nivåer av dynamisk smerte som pasienter med ren systemisk analgesi. Plasseringen av kateterspissen i forhold til inngrepet vil være avgjørende for optimal effekt, men av ressursmessige årsaker ble dette ikke undersøkt i vår studie. For å vurdere om epiduralanalgesi kan forventes å ha effekt, anbefales det å teste utbredelsen av den sensoriske blokaden gjerne med bruk av isbiter (20). Når det i journalen kun var dokumentert sensorisk undersøkelse hos tre av fire pasienter med epiduralanalgesi, får man inntrykk av at mange sykehus/avdelinger heller ikke har innarbeidet gode rutiner for oppfølging av epidural på sengepost. alle pasientene i studien var bedt om å angi smerteintensitet ved bruk av skala, at tre av fire ble tilbudt ekstra smertestillende og at $20 \%$ rapporterte at de hadde hatt mer smerter postoperativt enn forventet. Det kan derfor overraske at mer enn $90 \%$ er fornøyd med smertebehandlingen, selv om tilsvarende «paradokser» er rapportert tidligere (7). Det synes som om andre faktorer enn smerteintensitet som sådan har betydning for om pasientene er fornøyde med den postoperative smertebehandlingen. Mange av pasientene var sannsynligvis forberedt på sterke smerter, noe som gjenspeiles i at halvparten anga at smertene var som forventet Dersom de var informert om at operasjonen var vellykket, er det rimelig å anta at tilfredsheten ved at alt er vel overstått overskygger ubehaget med smerte. Videre ser vi at da pasientene ble spurt første postoperative dag anga de at «smerte akkurat nå» var mindre enn den «gjennomsnittlige smerten» første postoperative døgn, sannsynligvis fordi smertene gradvis avtok i intensitet. Dette kan oppleves som en fremgang, og kan forklare at pasientene er mer fornøyd enn om smertene er vedvarende eller tiltakende. En annen forklaring på at mange pasienter er fornøyde til tross for at de har opplevd sterke smerter, kan være at de enten på grunn av erfarte eller fryktede bivirkninger har avslått tilbud om ekstra smertestillende.

\section{Studiens styrke og svakheter}

Den fremste styrken ved denne undersøkelsen er at den inkluderer pasienter fra 14 norske sykehus av ulik størrelse, fordelt på alle helseregioner. Samtidig ble over $75 \%$ av pasientene som fylte inklusjonskriteriene, inkludert. Det at sykehusene som deltok i studien ble rekruttert via forfatternes nettverk $i$ Norsk smerteforening, kan ha ført til en skjevhet i hvilke sykehus som ble med i studien. Imidlertid er det naturlig å tro at en eventuell skjevhet går $\mathrm{i}$ retning av at de sykehusene som deltar i studien har ildsjeler blant personalet som er sterkt engasjert i postoperativ smertebehandling, og at disse sykehusene derfor har bedre postoperativ smertebehandling enn sykehus som ikke deltar i studien. Flertallet av pasientene ble inkludert i sykehus som tilhører Helse SørØst. Fordi postoperativ smertebehandling $i$ liten grad er standardisert innenfor de ulike helseforetakene og helseregionene, er det ikke grunn til å anta at denne skjevheten reduserer den eksterne validiteten og generaliserbarheten. I pasientmaterialet er det en viss heterogenisitet: Enkelte pasienter lå på oppvåkningsavdelinger mens andre lå på sengepost, og tiden fra avsluttet operasjon til datainnsamlingen var 12-30 timer. Disse forskjellene kan hos enkelte pasienter ha betydning for om analgetika er titrert til effekt og for hvorvidt pasienten ved datainnsamlingen fremdeles hadde smertelindrende effekt etter regionalanestesi. Enda snevrere inklusjonskriterier ville imidlertid ha ført til en vesentlig reduksjon $\mathrm{i}$ antall inkluderte pasienter uten automatisk å høyne den eksterne validiteten.

En annen svakhet er at spørsmålene om smerteintensitet slik de ble justert for undersøkelsen, ikke tidligere er validert. Det mangler gode, validerte instrumenter for kartlegging av postoperativ smerte som både fanger opp smerte i ro, dynamisk smerte, konsekvensene av smerte for funksjon/ mobilisering og pasientens vurdering av smertebehandlingen. Det at mange pasienter i studien har kronisk smerte både på og utenfor operasjonsstedet, kan også tenkes å påvirke rapporteringen av smerteintensitet dersom pasientene ikke greier å skille tydelig mellom sin kroniske og sin postoperative smerte.

Denne studien inkluderte ikke barn, pasienter med kognitiv svikt og pasienter som var behandlet dagkirurgisk. Vår evaluering var beregnet på pasienter med normal kognitiv funksjon, og barn og demente vil kreve andre verktøy. Ut fra klinisk erfaring er det grunn til å tro at pasienter uten evne til å verbalisere smerte og smerteintensitet, får dårligere smertelindring enn pasientene $\mathrm{i}$ vår undersøkelse. Vi ser derfor et klart behov for egne kartlegginger av smerte hos barn og pasienter med redusert kognitiv funksjon. Når det gjelder pasienter som blir behandlet dagkirurgisk, tyder svenske data på at disse pasientene i større grad enn pasientene i vår studie får multimodal smertebehandling $\mathrm{og}$ får smerteintensitet evaluert systematisk før utskrivning (21).

\section{Konklusjon}

At mange pasienter er fornøyd med smertebehandlingen, må ikke brukes som et argument for at behandlingen ved norske sykehus er tilfredsstillende. Ut ifra funnene $\mathrm{i}$ denne undersøkelsen ser vi følgende viktige forbedringsmuligheter:

- Bedre utnyttelse av effekten av NSAIDpreparater og steroider som ledd i en multimodal analgesi.

- Mer optimal epiduralanalgesi.

- Mer systematisk kartlegging og dokumentasjon av smerte.

- Systematisk preoperativ informasjon om postoperativ smerte og om risiko for kronisk postoperativ smerte.

Forbedringer på disse områdene krever innsats både fra anestesileger, leger i de kirurgiske spesialitetene og av sykepleiere ved oppvåkningsposter og kirurgiske sengeposter. Alle sykehus bør være bemannet med et kompetent smerteteam som kan veilede i behandlingen av pasienter med vanskelige smertetilstander, gjennomføre opplæring, utarbeide rutiner og ikke minst bidra til gode holdninger overfor pasienter som lider av smerte. 
Studien er utført i regi av forskningsutvalget i Norsk smerteforening og Nasjonalt kompetansesenter for sammensatte lidelser. Forfatterne takker for hjelp til datainnsamling fra de lokale koordinatorene og studiemedarbeiderne ved sykehusene som deltok i studien. Forfatterne takker også Berit Bjelkåsen ved Enhet for anvendt klinisk forskning, Norges teknisk-naturvitenskapelige universitet for å utarbeide registreringsskjemaet $i$ Teleform og for hjelp under innskanningen av skjemaene.

e-tab 1, e-tab 2, e-fig 1, e-ramme 1 og e-ramme 2 finnes på www.tidsskriftet.no.

\section{Olav Magnus S. Fredheim (1979)}

er cand.med. og har PhD. i smertemedisin. Han er lege i spesialisering i anestesiologi ved St. Olavs hospital og forsker ved Nasjonalt kompetansesenter for sammensatte lidelser, Norges teknisk-naturvitenskapelige universitet.

Ingen oppgitte interessekonflikter.

\section{Gunnvald Kvarstein (f. 1959)}

er dr.med. og overlege ved Avdeling for smertebehandling, Oslo universitetssykehus, Rikshospitalet. Han er leder i Norsk Smerteforening og representant i European Federation of IASP Chapters (EFIC).

Ingen oppgitte interessekonflikter.

\section{Eva Undall (f. 1961)}

er spesialsykepleier i intensivmedisin og har videreutdanning i kognitiv terapi. Hun er enhetsleder ved Smerteenheten, Sykehuset Telemark.

Ingen oppgitte interessekonflikter.

\section{Audun Stubhaug (f. 1957)}

er spesialist $i$ anestesiologi. Han er overlege ved Avdeling for smertebehandling. Oslo universitetssykehus.

Ingen oppgitte interessekonflikter.

\section{Tone Rustøen (f. 1956)}

er sykepleier. Hun er seniorforsker ved Akuttklinikken, Avdeling forskning og utdanning, Oslo universitetssykehus og professor ved Høgskolen i Oslo. .

Ingen oppgitte interessekonflikter.

\section{Petter C. Borchgrevink (f. 1952)}

er spesialist i anestesiologi og leder av Nasjonalt kompetansesenter for sammensatte lidelser, professor ved Forskningsgruppe smerte og palliasjon, Institutt for sirkulasjon og bildediagnostikk, Norges teknisk-naturvitenskapelige universitet, og overlege ved Avdeling for smerte og sammensatte lidelser, Klinikk for anestesi og akuttmedisin, St. Olavs hospital. Ingen oppgitte interessekonflikter.

\section{Litteratur}

1. Breivik H, Stubhaug A. Management of acute postoperative pain: still a long way to go! Pain 2008. 137: $233-4$

2. Liu SS, Wu CL. Effect of postoperative analgesia on major postoperative complications: a systematic update of the evidence. Anesth Analg 2007; 104: $689-702$.
3. Kehlet H, Jensen TS, Woolf CJ. Persistent postsurgical pain: risk factors and prevention. Lancet 2006; 367: 1618-25

4. Romundstad L, Breivik H, Roald $\mathrm{H}$ et al. Chronic pain and sensory changes after augmentation mammoplasty: long term effects of preincisional administration of methylprednisolone. Pain 2006; 124: $92-9$.

5. Holtan A Kongsgaard UE, Ohnstad HO Smerter hos kreftpasienter innlagt i sykehus. Tidsskr Nor Lægeforen 2005; 125: 416-8.

6. Holtan A, Aass N, Nordøy T et al. Prevalence of pain in hospitalised cancer patients in Norway: a national survey. Palliat Med 2007: 21: 7-13.

7. Fletcher D, Fermanian C, Mardaye A et al. A patient-based national survey on postoperative pain management in France reveals significant achievements and persistent challenges. Pain 2008; 137: 441-51.

8. Sommer M, de Rijke JM, van Kleef M et al. The prevalence of postoperative pain in a sample of 1490 surgical inpatients. Eur J Anaesthesiol 2008 . 25: $267-74$.

9. Gjeilo $\mathrm{KH}$, Stenseth R, Wahba A et al. Validation of the brief pain inventory in patients six months after cardiac surgery. J Pain Symptom Manage 2007: 34: 648-56

10. Klepstad P, Loge JH, Borchgrevink PC et al. The Norwegian brief pain inventory questionnaire: translation and validation in cancer pain patients. J Pain Symptom Manage 2002; 24: 517-25.

11. Mendoza TR, Chen C, Brugger A et al. The utility and validity of the modified brief pain inventory in a multiple-dose postoperative analgesic trial. Clin J Pain 2004; 20: 357-62

12. Derry C, Derry S, Moore RA et al. Single dose oral ibuprofen for acute postoperative pain in adults. Cochrane Database Syst Rev 2009; nr. 3: CD001548. doi: 10.1002/14651858.CD001548.pub2

13. Derry C, Derry S, Moore RA et al. Single dose oral naproxen and naproxen sodium for acute postoperative pain in adults. Cochrane Database Syst Rev 2009; nr. 1: CD004234. doi: 10.1002/ 14651858.CD004234.pub3

14. Derry P, Derry S, Moore RA et al. Single dose oral diclofenac for acute postoperative pain in adults. Cochrane Database Syst Rev 2009; nr. 2: CD004768. doi: 10.1002/14651858.CD004768.pub2.

15. Boursinos LA, Karachalios T, Poultsides L et al. Do steroids, conventional non-steroidal anti-inflammatory drugs and selective Cox-2 inhibitors adversely affect fracture healing? J Musculoskelet Neuronal Interact 2009; 9: 44-52.

16. Vuolteenaho K, Moilanen T, Moilanen E. Non-steroidal anti-inflammatory drugs, cyclooxygenase-2 and the bone healing process. Basic Clin Pharmacol Toxicol 2008; 102: 10-4.

17. Jakobsson J. Preoperative single-dose intravenous dexamethasone during ambulatory surgery: update around the benefit versus risk. Curr Opin Anaesthesiol 2010; 23: 682-6.

18. Niemi G, Breivik H. Adrenaline markedly improves thoracic epidural analgesia produced by a lowdose infusion of bupivacaine, fentanyl and adrenaline after major surgery. A randomised, doubleblind, cross-over study with and without adrenaline. Acta Anaesthesiol Scand 1998; 42: 897-909.

19. Niemi G, Breivik H. Epidural fentanyl markedly improves thoracic epidural analgesia in a lowdose infusion of bupivacaine, adrenaline and fentanyl. A randomized, double-blind crossover study with and without fentanyl. Acta Anaesthesiol Scand 2001; 45: 221-32

20. Breivik H. How to implement an acute pain service. Best Pract Res Clin Anaesthesiol 2002; 16 : 527-47.

21. Segerdahl M, Warrén-Stomberg M, Rawal N et al. Clinical practice and routines for day surgery in Sweden: results from a nation-wide survey. Acta Anaesthesiol Scand 2008; 52: 117-24. 